\title{
Bilateral Retroperitoneoscopic Lumbar Sympathectomy by Unilateral Access
}

\author{
Anibal W. Branco, Alcides J. Branco Filho, William Kondo, Luciano C. Stunitz, Paulo Douat \\ Jr., Marlos Coelho
}

Department of Urology and General Surgery, Cruz Vermelha Hospital, Curitiba, Parana, Brazil

\begin{abstract}
Purpose: Hyperhidrosis is a condition characterized by hyperactivity of the eccrine glands, causing an uncontrollable and excessive sweating, especially on the hands, plantar foot and groin, which can be confused with urinary incontinence. Standard treatment for plantar hyperhidrosis is the laparoscopic lumbar sympathectomy and the urologists are the besttrained surgeons to perform this procedure because they are familiar with the retroperitoneal anatomy. The goal of this video is to show our own technique of bilateral lumbar sympathectomy by unilateral access for plantar hyperhidrosis. Methods: The sample consisted of ten female patients who presented with plantar hyperhidrosis and were submitted to bilateral retroperitoneoscopic lumbar sympathectomy by unilateral access technique. All patients had already been submitted to a previous thoracic sympathectomy with no improvement of the plantar hyperhidrosis.

Results: Ten procedures were performed with this technique. In only one case, the bilateral retroperitoneal approach was required because of difficulty in locating the right nerve. Mean operative time and mean estimated blood loss were 68 minutes and $54 \mathrm{cc}$, respectively. We had no intraoperative complications and patients were discharged home 19.6 hours after surgery. Immediate warming of the feet was observed at the end of all procedures. On follow-up consultations, all patients referred complete resolution of the plantar hyperhidrosis. Only one patient developed compensatory hyperhidrosis in her back.

Conclusions: Retroperitoneoscopic lumbar sympathectomy by unilateral access seems to be feasible when performed by a surgeon with experience on advanced laparoscopy. Larger series comparing unilateral to bilateral access are necessary to establish the real benefits and potential disadvantages of this new technique.
\end{abstract}

Int Braz J Urol. 2011; 37 (Video \#3): 292_3

Available at: www.brazjurol.com.br/videos/march_april_2011/Kondo_292_293video.htm

\footnotetext{
Correspondence address:

Dr. William Kondo

Av. Getulio Vargas, 3163 / 21

Curitiba, PR, 80240-041, Brazil

E-mail: williamkondo@yahoo.com
} 


\section{EDITORIAL COMMENT}

In the video by Dr. Branco and colleagues, a novel technique using unilateral access of lumbar sympathectomy to treat plantar hyperhidrosis was very nicely depicted. Only one of their cases required a bilateral access to control the contralateral sympathetic chain. As they depict nicely in this video, this is an infrequent surgical procedure for urologists, however, we are quite familiar with retroperitoneal anatomy making us uniquely suited to conduct such surgery. An additional detail which would have been quite useful to know would be the follow-up of the surgically treated patients to determine the rate of refractory hyperhidrosis as well as "compensatory sweating", which remain two of the main concerns reported in other series. Similarly, histological information pertaining to the resected neural segments would be very pertinent as some prior reports would propose that one of the causes for refractory hyperhidrosis occurs when neural ganglia are resected (i.e. only the nerve) $(1,2)$. As this represents a new technique, it would be useful to determine the postoperative pain as well as the post-sympathectomy neuralgia, which are often temporary and contrast this with other techniques exhibiting long-term results.

One essential consideration to emphasize is that this procedure should be performed by skilled minimally invasive surgeons as the sympathetic chains run along the main retroperitoneal vessels, with potential devastating complications for those not familiar with this regional surgical anatomy.

\section{REFERENCES}

1. Rieger R, Pedevilla S, Pöchlauer S: Endoscopic lumbar sympathectomy for plantar hyperhidrosis. Br J Surg. 2009; 96: 1422-8.

2. Rieger R, Pedevilla S: Retroperitoneoscopic lumbar sympathectomy for the treatment of plantar hyperhidrosis: technique and preliminary findings. Surg Endosc. 2007; 21: 129-35.

Dr. Jose Jaime Correa Urologic Oncology Department Hospital Pablo Tobon Uribe Medellin, Colombia E-mail: jocorreao@uces.edu.co 